Article

\title{
Fumigant Toxicity of Lamiaceae Plant Essential Oils and Blends of Their Constituents against Adult Rice Weevil Sitophilus oryzae
}

\author{
Sung-Woong Kim ${ }^{1,+}$, Hyo-Rim Lee ${ }^{1}$, Myeong-Jin Jang ${ }^{2}$, Chan-Sik Jung ${ }^{2}$ and Il-Kwon Park ${ }^{1,3, *}$ \\ 1 Department of Forest Sciences, College of Agriculture and Life Sciences, Seoul National University, \\ Seoul 08826, Korea; ksw1945@naver.com (S.-W.K.); kazu21c@naver.com (H.-R.L.) \\ 2 Division of Forest Insect Pests and Diseases, Korea Forest Research Institute, Seoul 02455, Korea; \\ pokey12@snu.ac.kr (M.-J.J.); csjung@korea.kr (C.-S.J.) \\ 3 Research Institute of Agriculture and Life Science, College of Agriculture and Life Sciences, \\ Seoul National University, Seoul 08826, Korea \\ * Correspondence: parkik1@snu.ac.kr; Tel.: +82-2-880-4751; Fax: +82-2-873-3560 \\ † Present address: R \& D Center, Natural F \& P, Saemal-ro, Songpa-gu, Seoul 05799, Korea. \\ Academic Editor: Luca Forti \\ Received: 17 February 2016 ; Accepted: 10 March 2016 ; Published: 16 March 2016
}

\begin{abstract}
To find a new and safe alternative to conventional insecticides, we evaluated the fumigant toxicity of eight Lamiaceae essential oils and their constituents against the adult rice weevil Sitophilus oryzae. Of the eight species tested, hyssop (Hyssopus offcinalis), majoram (Origanum majorana), and Thymus zygis essential oils showed strong fumigant toxicity against S. oryzae adults at $25 \mathrm{mg} / \mathrm{L}$ air concentration. Constituents of active essential oils were analyzed by gas chromatography coupled to flame ionization detector (FID) and gas chromatography-mass spectrometry. A total of 13, 15, and 17 compounds were identified from hyssop, majoram, and Thymus zygis essential oils, respectively. Pinocamphone and isopinocamphone were isolated by open column chromatography. Among the test compounds, pinocamphone and isopinocamphone showed the strongest fumigant toxicity against $S$. oryzae. Sabinene hydrate, linalool, $\alpha$-terpineol, and terpinen- 4 -ol exhibited $100 \%$ fumigant toxicity against $S$. oryzae at $3.9 \mathrm{mg} / \mathrm{L}$ air concentration. The measured toxicity of the artificial blends of the constituents identified in hyssop, majoram, and Thymus zygis oils indicated that isopinocamphone, terpine-4-ol, and linalool were major contributors to the fumigant toxicity of the artificial blend, respectively.
\end{abstract}

Keywords: plant essential oils; lamiaceae; fumigant toxicity; rice weevil; artificial blends

\section{Introduction}

The rice weevil, Sitophilus oryzae (L.) is a serious insect pest of stored cereals around the world [1]. Several synthetic pesticides, including organophosphate, pyrethroids, or gaseous pesticides, have been widely used for the control of rice weevils [2]. Although these pesticides have greatly contributed to the management of the rice weevil population, they have caused several side effects including toxicity problems in humans and other animals, development of resistance, and environment pollution. Therefore, developing safe alternatives for conventional pesticides is urgently needed. Plant essential oils are good alternatives. They could be easily obtained by steam distillation and contain many bioactive compounds with fumigant toxicity against insect pests of stored cereals [1-5]. Another advantage of plant essential oils and their constituents is high volatility [6-8]. The high volatility of plant essential oils and their constituents reduces concern for their residues on stored grains.

Plants belonging to the family Lamiaceae are distributed around the world and are frequently aromatic. Many Lamiaceae plants have been used as traditional remedies for treating various ailments 
including coughs, digestive disorders, and heart disorders [9]. Plant essential oils of Lamiaceae have also been documented to show insecticidal and repellent activity against several insect pests [10-12]. Petrakis et al. [10] reported the effect of three Lamiaceae family members; i.e., Origanum majorana, Mentha pulegium, and Melissa offcinalis, on longevity and fecundity of the aphid Myzus persicae. Ogendo et al. [11] evaluated the fumigant and repellent effects of Ocimum gratissimum essential oil and its constituents, $\beta-(Z)$-ocimene and eugenol, on adults of Sitophilus oryzae, Tribolium castaneum, Oryzaephilus surinamensis, Rhyzopertha dominica, and Callosobruchus chinensis. Rozman et al. [12] investigated the toxicity of the naturally occurring compounds of Lamiaceae and Lauraceae essential oils against three stored-product insect pests including Sitophilus oryzae, Rhyzopertha dominica, and Tribolium castaneum.

In this study, we evaluated the fumigant toxicity of eight Lamiaceae plant essential oils and their constituents against the rice weevil S. oryzae to find new alternatives for conventional pesticides. Furthermore, fumigant toxicities of artificial blends made by constituents of active oils were also investigated to determine the main contributor to toxicity of active oils.

\section{Results and Discussion}

\subsection{Fumigant Toxicities of Lamiaceae Plant Essential Oils}

The fumigant toxicities of 8 Lamiaceae plant essential oils against adults of rice weevil are shown in Table 1. Among the test plant essential oils, hyssop, majoram and Thymus zygis oils showed $100 \%$ fumigant toxicity at $25 \mathrm{mg} / \mathrm{L}$ air concentration. The fumigant toxicities of hyssop and Thymus zygis oils were $100 \%$ and $74 \%$ at $6.5 \mathrm{mg} / \mathrm{L}$ air concentration but were reduced to $6 \%$ and $6 \%$ at $3.0 \mathrm{mg} / \mathrm{L}$ air concentration, respectively. The fumigant toxicity of majoram was $80 \%$ at $12.5 \mathrm{mg} / \mathrm{L}$ air concentration but decreased to $14 \%$ at $6.5 \mathrm{mg} / \mathrm{L}$ air concentration. Other oils revealed moderate or weak fumigant toxicity at $25 \mathrm{mg} / \mathrm{L}$ air concentration. Insecticidal or antimicrobial activities of plant essential oils tested in the current study have been documented in previous studies [13-18]. Insecticidal activities of majoram oil and its components against the German cockroach Blattella germanica were well studied by Jang et al. [13]. Antimicrobial and antifungal activities of Thymus zygis and hyssop essential oils have been documented in previous studies [14-18], but there has been no report on their insecticidal activity against stored product insect pests. Our results and previous studies indicated that the plant essential oils used in the current study could be good resources for managing the population of stored product insect pests. Furthermore, we report the insecticidal activities of hyssop and Thymus zygis essential oils for the first time.

Table 1. Fumigant toxicities of Lamiaceae plant essential oils against adults of the rice weevil S. oryzae.

\begin{tabular}{|c|c|c|c|c|}
\hline \multirow{2}{*}{ Plant Essential Oils } & \multicolumn{4}{|c|}{ Mortality $\left(\%\right.$, Mean \pm S.E., $\left.N^{a}=50\right)$} \\
\hline & $25^{b}$ & 12.5 & 6.5 & 3.0 \\
\hline Hyssop & $100 a^{c}$ & $100 a$ & $100 a$ & $6 \pm 4.9 a$ \\
\hline Lavender & $68 \pm 9.8 b$ & $28 \pm 9.8 c$ & $16 \pm 10.2 c$ & - \\
\hline Litesa & $70 \pm 8.9 b$ & $8 \pm 4.0 \mathrm{~d}$ & - & - \\
\hline Majoram & $100 \mathrm{a}$ & $80 \pm 12.6 b$ & $14 \pm 8.0 c$ & - \\
\hline Patchouli & od & $-d$ & - & - \\
\hline Sage spanish & $24 \pm 8.0 \mathrm{c}$ & - & - & - \\
\hline Salvia stenophylla & $\mathrm{Od}$ & - & - & - \\
\hline Thymus zygis & $100 \mathrm{a}$ & $96 \pm 4.9 a$ & $74 \pm 12.0 \mathrm{~b}$ & $6 \pm 8.0 \mathrm{a}$ \\
\hline \multirow{2}{*}{ Control } & $0 \mathrm{~d}$ & $0 \mathrm{~d}$ & $0 c$ & $0 \mathrm{a}$ \\
\hline & $\begin{array}{c}\mathrm{F}_{8,36}=307.20 \\
p<0.0001\end{array}$ & $\begin{array}{c}\mathrm{F}_{5,24}=187.15 \\
p<0.0001\end{array}$ & $\begin{array}{c}\mathrm{F}_{4,20}=121.87 \\
p<0.0001\end{array}$ & $\begin{array}{c}\mathrm{F}_{2,12}=1.636 \\
p=0.235\end{array}$ \\
\hline
\end{tabular}

${ }^{a}$ : Number of insects tested. ${ }^{b}: \mathrm{mg} / \mathrm{L}$ air concentration; ${ }^{c}$ : Means within a column followed by the same letters are not significantly different (Scheffe's test); ${ }^{d}$ : Not tested. 


\subsection{Chemical Analysis of Active Plant Essential Oils}

Chemical analyses of hyssop, majoram, and Thymus zygis essential oils are shown in Table 2. The main components of hyssop oils are isopinocamphone (35.68\%), followed by pinocamphone $(13.25 \%)$, camphor $(13.25 \%), \beta$-pinene (11.67\%), linalyl acetate $(1.40 \%)$, and myrcene $(1.32 \%)$. Daniele et al. [18] analyzed the chemical components of hyssop oils, and isopinocamphone $(29 \%)$, pinocamphone $(18.5 \%)$, $\beta$-pinene $(10.8 \%)$ and camphor $(5.3 \%)$ were identified as the main compounds. A previous study and ours showed similar results, although there was a difference in the composition rate and minor components. Galambosi and Peura [19] have already reported that there is a wide difference in the composition of plant essential oils according to production conditions, such as cultivation localities, harvesting date, storage time, climate, and soil factors. A total of 15 compounds were identified in majoram essential oil. The most abundant compound was terpinen-4-ol (22.96\%), followed by linalool $(15.32 \%), \gamma$-terpinene $(12.92 \%), p$-cymene $(6.37 \%), \alpha$-terpinene $(5.40 \%)$, limonene $(3.22 \%)$, $\alpha$-terpineol $(2.50 \%)$, and sabinene hydrate $(2.04 \%)$. The composition ratios of other compounds were less than $2 \%$. Chemical analysis of majoram oil was reported by El-seedi et al. [20]. The composition ratio of terpinen-4-ol (55.6\%) was the highest, followed by $\alpha$-terpineol $(9.5 \%)$, linalool $(3.7 \%), \gamma$-terpinene $(3.6 \%)$, and p-menth-2-en-1-ol (3.0\%). Linalool $(40.14 \%)$ was identified as the most abundant component in Thymus zygis oil. Other compounds including terpinen-4-ol (8.83\%), myrcene $(5.88 \%)$, sabinene hydrate $(5.35 \%)$, and $p$-cymene $(4.14 \%)$ were identified as main components. Gonçalves et al. [15] investigated the antifungal and cytotoxic activity of Thymus zygis oils and its components. Linaool $(30.0 \%), 1,8$-cineole $(12.0 \%)$, p-cymene $(11.0 \%)$, thymol $(8.0 \%)$, camphene $(3.9 \%)$, and $\gamma$-terpinene (3.8\%) were determined to be the main components.

Table 2. Chemical analysis of active essential oils.

\begin{tabular}{ccccccc}
\hline \multirow{2}{*}{ No. } & \multirow{2}{*}{ Compound } & \multicolumn{2}{c}{ Retention Index } & \multicolumn{3}{c}{ Composition Ratio (\%) } \\
\cline { 3 - 6 } & & DB-1MS/Lit & HP-Innowax & Hyssop & Majoram & Thymus zygis \\
\hline 1 & $\alpha$-Pinene & $929 / 940^{\mathrm{a}}$ & 1020 & 0.65 & 0.44 & 3.80 \\
2 & Camphene & $941 / 950^{\mathrm{a}}$ & 1063 & 0.11 & - & 1.12 \\
3 & $\beta$-Pinene & $968 / 975^{\mathrm{a}}$ & 1107 & 11.67 & 1.18 & 0.34 \\
4 & Myrcene & $982 / 981^{\mathrm{a}}$ & 1165 & 1.32 & 1.02 & 5.88 \\
6 & $\alpha$-Terpinene & $1007 / 1011^{\mathrm{a}}$ & 1180 & $-\mathrm{d}$ & 5.40 & 1.45 \\
7 & p-Cymene & $1011 / 1014^{\mathrm{a}}$ & 1273 & 0.11 & 6.37 & 4.14 \\
8 & 1,8 -Cineole & $1018 / 1026^{\mathrm{a}}$ & 1208 & - & 1.12 & 0.61 \\
9 & Limonene & $1020 / 1018^{\mathrm{b}}$ & 1199 & 0.92 & 3.22 & 2.77 \\
10 & $\gamma$-Terpinene & $1048 / 1050^{\mathrm{a}}$ & 1247 & - & 12.92 & 3.13 \\
11 & Sabinene hydrate & $1051 / 1056^{\mathrm{a}}$ & 1465 & - & 2.04 & 5.35 \\
12 & Terpinolene & $1077 / 1081^{\mathrm{a}}$ & 1284 & - & 1.07 & 0.84 \\
13 & Linalool & $1084 / 1083^{\mathrm{a}}$ & 1560 & - & 15.32 & 40.14 \\
14 & Camphor & $1117 / 1128^{\mathrm{a}}$ & 1520 & 13.25 & - & 0.36 \\
15 & Pinocamphone & $1135 / 1142^{\mathrm{a}}$ & 1520 & 13.25 & - & - \\
16 & Isopinocamphone & $1145 / 1157^{\mathrm{a}}$ & 1550 & 35.68 & - & - \\
17 & Terpinen-4-ol & $1160 / 1166^{\mathrm{a}}$ & 1610 & 0.17 & 22.96 & 8.83 \\
18 & $\alpha$-Terpineol & $1171 / 1178^{\mathrm{a}}$ & 1705 & 0.24 & 2.50 & 2.30 \\
19 & Linalyl acetate & $1240 / 1240^{\mathrm{a}}$ & 1560 & 1.40 & 0.85 & 0.62 \\
20 & $\beta$-Caryophyllene & $1414 / 1429^{\mathrm{a}}$ & 1599 & - & 1.58 & 1.07 \\
21 & $\alpha$-Humulene & $1447 / 1450^{\mathrm{c}}$ & 1672 & 0.16 & - & - \\
& Sum & & & 78.93 & 77.99 & 82.75 \\
\hline
\end{tabular}

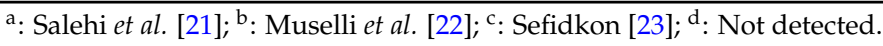

\subsection{Fumigant Toxicities of Constituents Identified from Active Plant Essential Oils}

The fumigant toxicities of constituents from three active oils and organophosphorus insecticide dichlorvos are shown in Table 3. Among the test compounds, isopinocamphone and pinocamphone showed $100 \%$ fumigant toxicity against S. oryzae adults at whole test concentrations, although no 
mortality was observed at $0.0 .375 \mathrm{mg} / \mathrm{L}$ air concentration (data not shown here). The insecticidal activities of $\alpha$-terpineol and terpinen-4-ol were $100 \%$ and $88 \%$ at $3 \mathrm{mg} / \mathrm{L}$ air concentration but were reduced to $18 \%$ and $24 \%$ at $1.5 \mathrm{mg} / \mathrm{L}$ air concentration, respectively. Linalool, camphor, camphene, and sabinene hydrate exhibited $100 \%$ fumigant toxicity at $12.5 \mathrm{mg} / \mathrm{L}$ air concentration but showed weak activity at $6.5 \mathrm{mg} / \mathrm{L}$ air concentration. The fumigant toxicity of terpinolene was $98 \%$ at $25 \mathrm{mg} / \mathrm{L}$ air concentration, but decreased to $20 \%$ at $12.5 \mathrm{mg} / \mathrm{L}$ air concentration. Other compounds exhibited moderate or weak fumigant toxicity at $25 \mathrm{mg} / \mathrm{L}$ air concentration. Dichlorvos showed 100\% fumigant toxicity at whole test concentrations. Kim et al. [24] already reported that the $\mathrm{LC}_{50}$ value of dichlorvos against rice weevil adults was $0.0081 \mathrm{mg} / \mathrm{L}$ air concentration. Insecticidal activities of essential oil constituents against rice weevil are well documented [1,4,5]. Lee et al. [5] reported that 1,8-cineole, $p$-cymene, limonene, linalool, $\alpha$-terpinene, $\alpha$-terpineol, and terpinen-4-ol exhibited fumigant toxicity against $S$. oryzae adults. However, fumigant toxicity of 1,8-cineole, $p$-cymene, and limonene was not observed in this study. $\mathrm{LC}_{50}$ values of camphene and camphor against $S$. oryzae adults were $>100 \mathrm{mg} / \mathrm{L}$ air concentration in a previous study [4], but the fumigant toxicities of two compounds in this study were stronger than those of a previous study. This difference might be attributed to the use of different strains of S. oryzae. Although essential oil and solvent extracts of hyssop have been documented to show antimicrobial, antioxidant, antiviral, cytotoxicity, and $\alpha$-glucosidase inhibitory activity, the biological activities of pinocamphone and isopinocamphone, main constituents of hyssop oil, have not been well documented [25]. In this study, we isolated two main components from hyssop oil and determined their fumigant toxicities against $S$. oryzae adults for the first time.

Table 3. Fumigant toxicities of constituents identified from active plant essential oils against adults of the rice weevil S. oryzae.

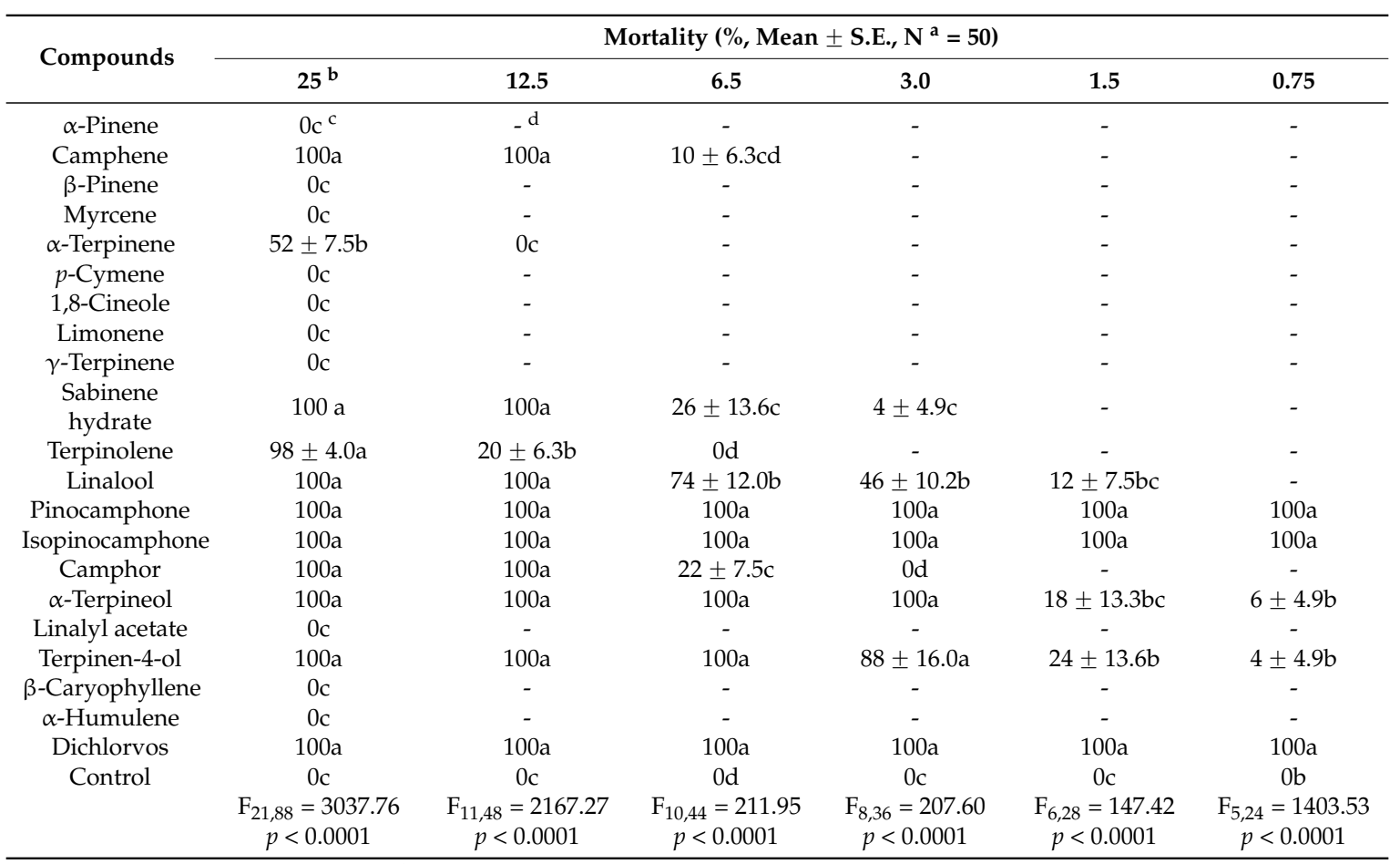

${ }^{a}$ : Number of insects tested; ${ }^{b}: \mathrm{mg} / \mathrm{L}$ air concentration; ${ }^{\mathrm{c}}$ : Means within a column followed by the same letters

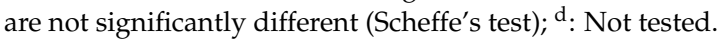

The structure-activity relationships of essential oil constituents have been well documented [26,27]. Usually, the insecticidal or nematicidal properties of essential oil constituents with aldehyde, ketone, or alcohol functional groups are stronger than those of monoterpenoids belonging to hydrocarbons. Kim et al. [28] also reported that the fumigant toxicities of oil constituents with aldehyde, ketone, and 
alcohol groups were much stronger than those of hydrocarbons such as $\alpha$-pinene, $\beta$-pinene, myrcene, $p$-cymene, and limonene against rice weevil adults. In this study, similar results were observed. The fumigant toxicities of oil constituents belonging to alcohol or ketone groups were much stronger than those of hydrocarbon terpenoids. However, a different relationship was found in a test with the Asian tiger mosquitoe, Aedes albopictus. Seo et al. [7] reported that larvicidal activities of hydrocarbon terpenoids were stronger than those of alcohols, aldehydes, and ketones. This result indicated that essential oil constituents might have different modes of action according to the insect species.

\subsection{Comparative Toxicities of Artificial Blends}

The fumigant toxicities of artificial blends against rice weevils are shown in Figure 1. There was no significant difference in the fumigant toxicities between artificial mixtures including all constituents and essential oils (Figure 1). In a component elimination test of hyssop oil, omission of isopinocamphone caused a significant decrease in the fumigant toxicity $\left(\mathrm{F}_{15,64}=774.92, p<0.0001\right)$. This result indicated that isopinocamphone was a major contributor to the fumigant toxicity of hyssop oil. Although the decrease in fumigant toxicity was lower compared to that of isopinocamphone, omission of pinocamphone also caused a significant difference in fumigant toxicity (Figure 1A). This result showed that pinocamphone was the second main contributor to the fumigant toxicity of hyssop oil. Omission of other compounds from the full mixture did not cause a significant difference in the fumigant toxicity of the blend. For majoram oil, a component elimination assay showed that the omission of terpinen-4-ol from the full mixture caused a significant decrease in the fumigant toxicity of the blend $\left(\mathrm{F}_{17,72}=38.125\right.$, $p<0.0001$ ). Omission of other constituents did not cause a significant difference in fumigant toxicity. This result indicated that terpinen-4-ol was the major contributor to fumigant toxicity of majoram oil. Omission of linalool, myrcene, and p-cymene from the artificial full mixture of Thymus zygis oil components showed a significant difference in the fumigant toxicity of the blend $\left(\mathrm{F}_{17,72}=37.70\right.$, $p<0.0001$ ). Linalool was the major contributor to the fumigant toxicity of Thymus zygis oil, followed by $p$-cymene and myrcene. This result indicated that linalool, $p$-cymene and myrcene act synergistically in terms of fumigant toxicity against rice weevils. A comparative toxicity test of artificial blends showed that there was a major contributor to the fumigant toxicity of active oils, and this information could be very useful for determining the minimum ratio of major contributors. Furthermore, our results also indicated that components of essential oils act synergistically in fumigant toxicity.

\section{Materials and Methods}

\subsection{Plant Essential Oils and Chemicals}

Essential oils of patchouli (Pogostemon patchouli), Salvia stenophylla, and Thymus zygis were purchased from Oshadhi (Bühl/Baden, Germany, www.oshadhi.eu). Hyssop (Hyssopus officinalis), litesa (Litsea cubeba), lavender (Lavandula officinalis), majoram (Origanum majorana L.), and sage spanish (Salvia officinalis), were purchased from JinArome (Anyang, Korea, www.jinarome.com). $\alpha$-Pinene (purity, 99\%), camphene (80\%), $\beta$-pinene (99\%), p-cymene (99\%), 1,8-cineole (99\%), limonene (97\%), camphor (99\%), and $\alpha$-humulene (96\%) were obtained from Sigma-Aldrich (Milwaukee, WI, USA). $\alpha$-Terpinene (85\%), and sabinene hydrate (97\%) were purchased from Fluka (Buchs, Switzerland). (-)- $\alpha$-Phellandrene (65\%), terpinolene (85\%), ( \pm )-terpinen-4-ol (95\%), and $\beta$-caryophyllene $(90 \%)$ were obtained from the Tokyo chemical industry (Tokyo, Japan). Acetone was purchased from Merck (Darmstadt, Germany) (99.8\%).

\subsection{Insects}

A culture of $S$. oryzae was maintained in the laboratory without exposure to any insecticide. The weevils were reared on unpolished rice in plastic cages $(60 \times 40 \times 40 \mathrm{~cm})$ at $25 \pm 1^{\circ} \mathrm{C}$ and $60 \%$ relative humidity (RH) under a 16:8 h light:dark cycle. 

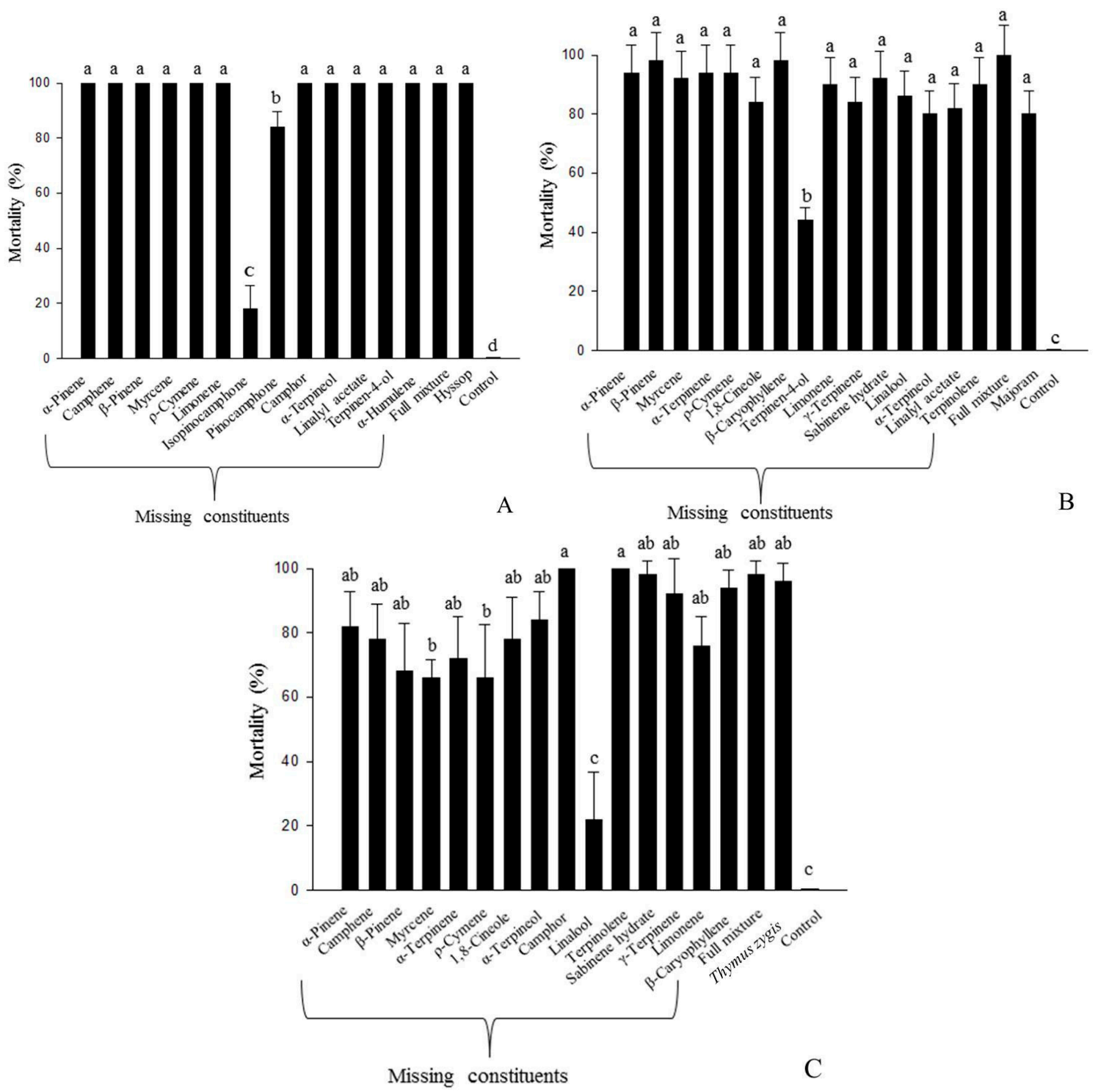

Figure 1. Fumigant toxicities of hyssop (A); majoram (B); Thymus zygis oil (C), a full mixture, and selected blends of the constituents in rice weevil adults with $48 \mathrm{~h}$ of treatment. The concentration of hyssop, majoram, and Thymus zygis oil was $12.5 \mathrm{mg} / \mathrm{L}$ air. The concentrations of the full mixture of hyssop, majoram, and Thymus zygis oil were 9.86, 9.74, and $10.34 \mathrm{mg} / \mathrm{L}$ air, respectively. The concentrations of the other blends were determined by removing each constituent equivalent to the ratio identified in hyssop, majoram, and Thymus zygis oil. Mean values corresponding to each treatment with different letters are significantly different from each other (hyssop oil: $\mathrm{F}_{15,64}=774.92, p<0.0001$; majoram oil: $\mathrm{F}_{17,72}=38.125, p<0.0001$; Thymus zygis oil: $\mathrm{F}_{17,72}=37.70, p<0.0001$; Scheffé's test).

\subsection{Gas Chromatography}

Gas chromatography analysis of hyssop, majoram, and Thymus zygis was performed using an Agilent 7890N (Santa Clara, CA, USA) equipped with a flame ionization detector (FID). A $1 \mu \mathrm{L}$ sample of the essential oil dissolved in hexane (essential oil:hexane $=1: 200, v / v$ ) was injected. DB-1MS (30 m $\times 0.25 \mathrm{~mm}$ i.d., film thickness: $0.25 \mu \mathrm{m}, \mathrm{J} \& \mathrm{~W}$ Scientific, Santa Clara, CA, USA) and HP-INNOWAX columns ( $30 \mathrm{~m} \times 0.25 \mathrm{~mm}$ i.d., film thickness: $0.25 \mu \mathrm{m}, \mathrm{J} \& \mathrm{~W}$ Scientific) were individually used for separation of the essential oil constituents. The oven temperature was programmed as isothermal at $40{ }^{\circ} \mathrm{C}$ for $1 \mathrm{~min}$, raised to $250{ }^{\circ} \mathrm{C}$ at a rate of $6{ }^{\circ} \mathrm{C} / \mathrm{min}$, and held at this temperature for $4 \mathrm{~min}$. Helium was used as the carrier gas, and the flow rate was $1.5 \mathrm{~mL} / \mathrm{min}$. The 
retention indices were obtained in relation to a homologous series of $n$-alkanes $\left(C_{7}-C_{20}\right)$, under the same operating conditions used for the GC-FID analysis. The components were further confirmed by enhancing the integrated area by co-injection with the essential oil and standard samples.

\subsection{Gas Chromatography-Mass Spectrometry}

A gas chromatograph (Agilent 7890A, Santa Clara, CA, USA) and a mass spectrometer (Agilent 5975C MSD) were used for comparing the mass spectra of each peak to those obtained from the NIST MS library using a DB-1MS column ( $30 \mathrm{~m} \times 0.25 \mathrm{~mm}$ i.d., film thickness: $0.25 \mu \mathrm{m}$, J \& W Scientific). A $1 \mu \mathrm{L}$ sample of the essential oil dissolved in hexane (essential oil:hexane $=1: 200, v / v$ ) was injected. The oven temperature was the same as that used for the GC-FID analysis. The flow rate of the carrier gas (helium) was $1.0 \mathrm{~mL} / \mathrm{min}$. The GC column effluent was introduced directly into the MS source via a transfer line at $250^{\circ} \mathrm{C}$. Ionization was obtained by electron impact $(70 \mathrm{eV}$, source temperature: $230^{\circ} \mathrm{C}$ ), and the scan range was $41-400 \mathrm{amu}$.

\subsection{Isolation of Isopinocamphone and Pinocamphone}

To isolate isopinocamphone and pinocamphone, which were not commercially available, we used open column chromatography (Figure 2). Small amounts of hyssop (5 g) oil were subjected to $\mathrm{SiO}_{2}$ gel column chromatography (hexane/ether 100/0 $\rightarrow 0 / 100)$. Almost pure iospinocamphone $(0.222 \mathrm{~g}$, $97 \%$ ) was isolated from the diethyl ether $2 \%$ fraction. The $\mathrm{H} 2$ fraction was further subjected to $\mathrm{SiO}_{2}$ gel column chromatography, and pinocamphone $(87 \mathrm{mg}$, mixture of $30 \%$ isopinocamphone) was isolated from the ether $1.5 \%$ fraction. Purity of pinocamphone and isopinocamphone was determined with gas chromatography. Isolated compounds were identified by gas chromatography-mass spectrometry and used for fumigant and comparative toxicity tests.

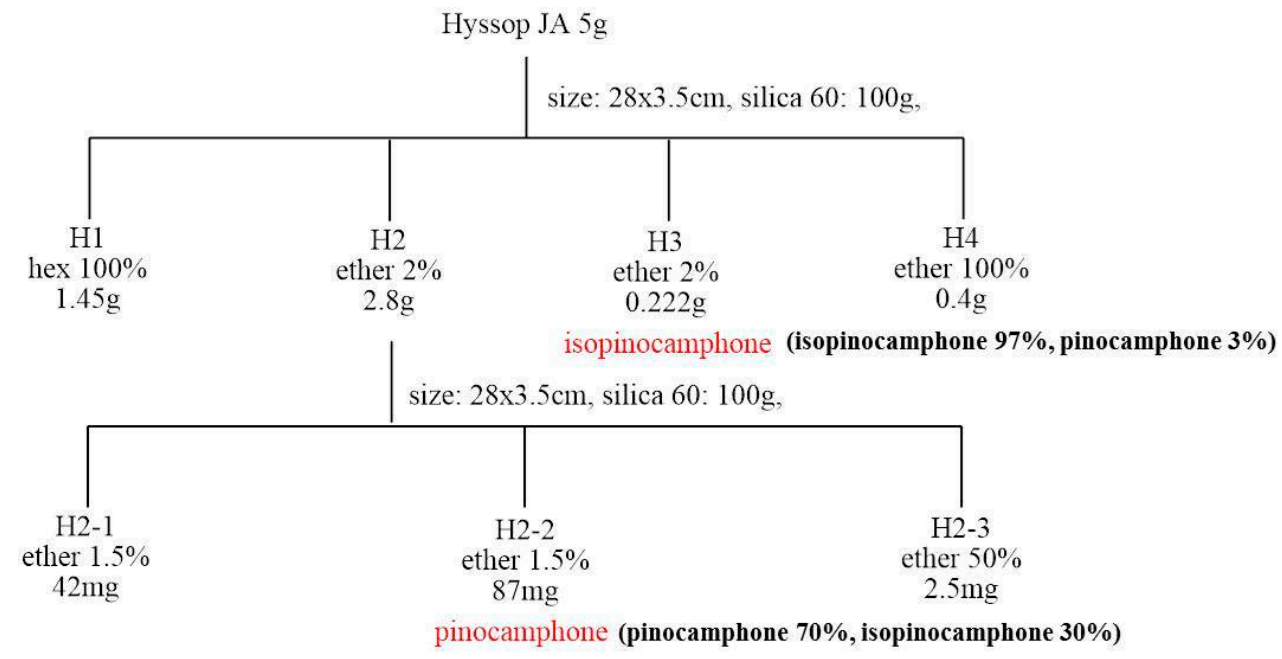

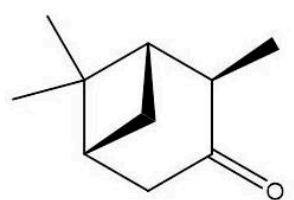

pinocamphone

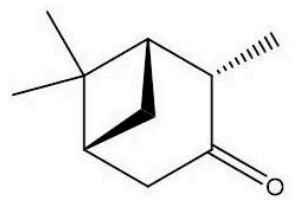

isopinocamphone

Figure 2. Isolation procedure of isopinocamphone and pinocamphone, and their chemical structures. 


\subsection{Fumigant Toxicity Test}

Lamiaceae plant essential oils or their constituents were applied to a paper disc $(8 \mathrm{~mm}$, Advantec, Tokyo, Japan) that was placed in the bottom lid of a glass cylinder (diameter, $5 \mathrm{~cm}$; height, $10 \mathrm{~cm}$ ) with a wire sieve fitted $3.5 \mathrm{~cm}$ above the bottom. The lid of the glass cylinder was then sealed with para-film (Pechiney Plastic Packaging Company, Chicago, IL, USA). Ten rice weevil adults (10-20 days old) were placed on the sieve, and this prevented direct contact of the rice weevils with the test oils or compounds. Glass cylinders were kept at $25 \pm 1{ }^{\circ} \mathrm{C}$ and $60 \% \mathrm{RH}$. Adult rice weevils were considered dead if their appendages did not move when prodded with a paintbrush. Cumulative mortality was determined $48 \mathrm{~h}$ after treatment. All treatments were replicated five times.

\subsection{Comparative Toxicity Test}

To know the role of each constituent for fumigant toxicity against rice weevils, we made artificial blends made by all available constituents of hyssop, majoram and Thymus zygis essential oils. We also made a number of blends that omitted one constituent from the mixture of all constituents (Figure 1). Blends were based on the natural composition of constituents determined by GC-FID (Table 2). The concentrations of the full mixture of hyssop, majoram, and Thymus zygis essential oils were $9.86 \mathrm{mg} / \mathrm{L}$, $9.74 \mathrm{mg} / \mathrm{L}$, and $10.34 \mathrm{mg} / \mathrm{L}$ air concentration, respectively. The concentrations of other artificial blends were prepared by removing each constituent equivalent to the ratio identified in hyssop, majoram, and Thymus zygis essential oils.

\subsection{Statistical Analysis.}

The percentage of mortality for $S$. oryzae adults was transformed to arcsine square-root values prior to analysis of variance (ANOVA). Treatment mean values were compared and separated using Scheffe's test. Mean $( \pm S E)$ values of untransformed data have been reported. Statistical analyses were performed using IBM SPSS Statistics 23.0 (2015).

\section{Conclusions}

Of the eight species belonging to Lamiaceae, hyssop (Hyssopus offcinalis), majoram (Origanum majorana), and Thymus zygis essential oils showed strong fumigant toxicity against S. oryzae adults. Among identified constituents from active oils, pinocamphone and isopinocamphone showed the strongest fumigant toxicity against $S$. oryzae. The measured toxicity of the artificial blends of the constituents identified in hyssop, majoram, and Thymus zygis oils indicated that isopinocamphone, terpine-4-ol, and linalool were major contributors to the fumigant toxicity of the artificial blend, respectively.

Acknowledgments: This work was supported by a Research Resettlement Fund for the new faculty of Seoul National University (Project No.: 500-20140209) to Il-Kwon Park..

Author Contributions: Sung-Woong Kim and Il-Kwon Park designed the experiments and wrote the manuscript. Sung-Woong Kim analyzed the chemical composition of plant essential oils and isolated compounds. Sung-Woong Kim, Myeong-Jin Jang, and Chan-Sik Jung performed bioassays. Sung-Woong Kim, Hyo-Rim Lee, and Il-Kwon Park analyzed the data.

Conflicts of Interest: The authors declare no conflict of interest.

\section{References}

1. Park, I.K.; Lee, S.G.; Choi, D.H.; Park, J.D.; Ahn, Y.J. Insecticidal activities of constituents identified in the essential oil from leaves of Chamaecyparis obtusa against Callosobruchus chinensis (L.) and Sitophilus oryzae (L.). J. Stored Prod. Res. 2003, 39, 375-384. [CrossRef]

2. Shaaya, E.; Kostjukovsky, M.; Eilberg, J.; Sukprakarn, C. Plant oils as fumigants and contact insecticides for the control of stored-product insects. J. Stored Prod. Res. 1997, 33, 7-15. [CrossRef] 
3. Rajendran, S.; Sriranjini, V. Plant products as fumigants for stored-produce insect control. J. Stored Prod. Res. 2008, 44, 126-135. [CrossRef]

4. Abdelgaleil, S.A.M.; Mohamed, M.I.E.; Badawy, M.E.I.; El-arami, S.A.A. Fumigant and contact toxicities of monoterpenes to Sitophilus oryzae (L.) and Tribolium castaneum (Herbst) and their inhibitory effects on acetylcholinesterase activity. J. Chem. Ecol. 2009, 35, 518-525. [CrossRef] [PubMed]

5. Lee, B.H.; Choi, W.S.; Lee, S.E.; Park, B.S. Fumigant toxicity of essential oils and their constituents compounds towards the rice weevil, Sitophilus oryzae (L.). Crop Prot. 2001, 20, 317-320. [CrossRef]

6. Park, I.K.; Choi, K.S.; Kim, D.H.; Choi, I.H.; Kim, L.S.; Bak, W.C.; Choi, J.W.; Shin, S.C. Fumigant activity of plant essential oils and components from horseradish (Armoracia rusticana), anise (Pimpinella anisum) and garlic (Allium sativum) oils against Lycoriella ingenua (Diptera: Sciaridae). Pest Manag. Sci. 2006, 62, 723-728. [CrossRef] [PubMed]

7. Seo, S.M.; Jung, C.S.; Kang, J.; Lee, H.R.; Kim, S.W.; Hyun, J.; Park, I.K. Larvicidal and acetylcholinesterase inhibitory activities of Apiaceae plant essential oils and their constituents against Aedes albopictus and formulation development. J. Agric. Food Chem. 2015, 63, 9977-9986. [CrossRef] [PubMed]

8. Park, H.M.; Park, I.K. Larvicidal activity of Amyris balsamifera, Daucus carota and Pogostemon cablin essential oils and their components against Culex pipiens pallens. J. Asia-Pac. Entomol. 2012, 15, 631-634. [CrossRef]

9. Çalmaşur, Ö.; Aslan, İ.; Şahin, F. Insecticidal and acaricidal effect of three Lamiaceae plant essential oils against Tetranychus urticae Koch and Bemisia tabaci Genn. Ind. Crop. Prod. 2006, 23, 140-146. [CrossRef]

10. Petrakis, E.A.; Kimbaris, A.C.; Perdikis, D.C.; Lykouressis, D.P.; Tarantilis, P.A.; Polissiou, M.G. Response of Myzus persicae (Sulzer) to three Lamiaceae essential oils obtained by microwave-assisted and conventional hydrodistillation. Ind. Crop. Prod. 2014, 62, 272-279. [CrossRef]

11. Ogendo, J.O.; Kostyukovsky, M.; Ravid, U.; Matasyoh, J.C.; Deng, A.L.; Omolo, E.O.; Kariuki, S.T.; Shaaya, E. Bioactivity of Ocimum gratissimum L. oil and two of its constituents against five insect pests attacking stored food products. J. Stored Prod. Res. 2008, 44, 328-334. [CrossRef]

12. Rozman, V.; Kalinovic, I.; Korunic, Z. Toxicity of naturally occurring compounds of Lamiaceae and Lauraceae to three stored-product insects. J. Stored Prod. Res. 2007, 43, 349-355. [CrossRef]

13. Jang, Y.S.; Yang, Y.C.; Choi, D.S.; Ahn, Y.J. Vapor phase toxicity of majoram oil compounds and their related monoterpenoids to Blatella germanica (Orthoptera: Blattellidae). J. Agric. Food Chem. 2005, 53, 7892-7898. [CrossRef] [PubMed]

14. Rota, M.C.; Herrera, A.; Martínez, R.M.; Sotomayor, J.A.; Jordán, M.J. Antimicrobial activity and chemical composition of Thymus vulgaris, Thymus zygis and Thymus hyemalis essential oils. Food Cont. 2008, 19, 681-687. [CrossRef]

15. Gonçalves, M.J.; Cruz, M.T.; Cavaleiro, C.; Lopes, M.C. Salgueiro, L. Chemical, antifungal and cytotoxic evaluation of the essential oil of Thymus zygis subsp. Sylvestris. Ind. Crop. Prod. 2010, 32, 70-75. [CrossRef]

16. Kizil, S.; Hasimi, N.; Tolam, V.; Kilinc, E.; Karatas, H. Chemical composition, antimicrobial and antioxidant activities of hyssop (Hyssopus officinalis L.) essential oil. Not. Bot Hot. Agrobo. Cluj. 2010, 38, 99-103.

17. Motiejunaite, O.; Kalediene, L. Antimicrobial activity of Lamiaceae plant essential oils on Aspergillus niger growth. Biol. Sci. 2003, 51, 237-242.

18. Daniele, F.; Ricci, D.; Epifano, F.; Massimo, C. Composition and antifungal activity of two essential oils of hyssop (Hyssopus officinalis L.). J. Essential Oil Res. 2004, 16, 617-622.

19. Galambosi, B.; Peura, P. Agrobotanical features and oil content of wild and cultivated forms of caraway (Carum carvi L.). J. Essential Oil Res. 1996, 8, 389-397. [CrossRef]

20. El-seedi, H.R.; Khalil, N.S.; Azeem, M.; Taher, E.A.; Göransson, U.; Pålsson, K.; Borg-Karlson, A.K. Chemical composition and repellency of essential oils from four medicinal plants against Ixodes ricinus Nymphs (Acari: Ixodidae). J. Med. Entomol. 2012, 49, 1067-1075. [CrossRef] [PubMed]

21. Salehi, P.; Fakhari, A.R.; Ebrahimi, S.N.; Heydari, R. Rapid essential oil screening of Rosmarinus officinalis L. by hydrodistillation-headspace solvent microextraction. Flavor Fragr. J. 2007, 22, 280-285. [CrossRef]

22. Muselli, A.; Hoi, T.M.; Cu, L.D.; Moi, L.D.; Bessiere, J.M.; Bighelli, A. Composition of the essential oil of Acanthopanax trifoliatus (L.) Merr. (Araliacaea) from Vitenam. Flavor Fragr. J. 1999, 14, 41-44. [CrossRef]

23. Sefidkon, F. Essential oil of Lantana camara L. occurring in Iran. Flavour Fragr. J. 2002, 17, 78-80. [CrossRef]

24. Kim, J.; Park, I.K. Fumigant toxicity of Korean medicinal plant essential oils and components from Asiasarum sieboldin root against Sitophilus oryzae L. Flavour Fragr. J. 2008, 23, 79-83. [CrossRef] 
25. Fathiazad, F.; Hamedeyazdan, S. A review on Hyssopus officinalis L.: Composition and biological activities. Afr. J. Pharm. Pharmacol. 2011, 5, 1959-1966. [CrossRef]

26. Choi, I.H.; Kim, J.; Shin, S.C.; Park, I.K. Nematicidal activity of monoterpenoids against the pine wood nematode (Bursaphelenchus xylophilus). Russ. J. Nematol. 2007, 15, 35-40.

27. Seo, S.M.; Kim, J.; Lee, S.G.; Shin, S.C.; Park, I.K. Fumigant antitermitic activity of plant essential oils and components from Ajowan (Trachyspermum ammi), Allspice (Pimenta dioica), caraway (Carum carvi), dill (Anethum graveolens), Geranium (Pelargonium graveolens), and Litsea (Litsea cubeba) oils against Japanese termite (Reticulitermes speratus Kolbe). J. Agric. Food Chem. 2009, 57, 6596-6602. [PubMed]

28. Kim, S.W.; Kang, J.; Park, I.K. Fumigant toxicity of Apiaceae essential oils and their constituents against Sitophilus oryzae and their acetylcholinesterase inhibitory activity. J. Asia Pac. Entomol. 2013, 16, 443-448. [CrossRef]

Sample Availability: Samples of the compounds (except pinocamphone and isopinocamphone) are available from the authors.

(c) 2016 by the authors; licensee MDPI, Basel, Switzerland. This article is an open access article distributed under the terms and conditions of the Creative Commons by Attribution (CC-BY) license (http://creativecommons.org/licenses/by/4.0/). 